\title{
“They Will Wonder What Kind of a Girl I Am": Adolescent Perceptions towards Contraceptive Use in Nairobi
}

\author{
Joyce W. Kinaro \\ University of Nairobi, Nairobi, Kenya \\ Email: jkinaro@yahoo.com
}

Received October 29, 2012; revised November 30, 2012; accepted December 8, 2012

\begin{abstract}
As in other developing countries, contraceptive use among adolescents is low and only one in twenty adolescents is reported to use contraceptives in Kenya. Pregnancies early in life expose adolescents to health complications. Establishing perceptions that affect contraception and factors that influence those perceptions is important in developing appropriate programs and policies to increase contraceptive use prevalence among adolescents. We used primary data from a household survey using a systematic random sampling in eight administrative divisions in Nairobi County in 2010. The study utilized information collected using structured interviews, focus group discussions (FGDs) and in-depth interviews (IDIs). The findings revealed that perceptions on parental approval, adolescent approval, ability to get contraceptives for self, knowledge of how to use contraceptives and sexual partner communication had significant effect on contraception. The narratives showed that parents, teachers and service providers had negative perceptions and discouraged contraception among adolescents thereby influencing use. Parents and teachers had inadequate knowledge and skills to communicate sexuality messages creating potential environment likely to have indirect negative influence on adolescents' perceptions on contraception.
\end{abstract}

Keywords: Sexuality Education; Parent Child Communication; Perceptions; Contraceptive Use; Sexual Partner Communication

\section{Introduction}

The use of contraceptives among 15 - 19 years old adolescents is low worldwide. Most studies show perceptions are a major factor influencing contraceptive use among adolescents. However, inadequate literature exists on perceptions and factors in the environment that influence adolescents' perceptions and their impact on contraceptive use. Perception formation theory [1-3] indicates that behavior is influenced by personal factors and other environmental dynamics. Perceptions about contraceptive use are influenced by information adolescents receive from the family, school and the media [1]. However, much sexually-related information has been found to be inaccurate, ambiguous and sometimes misleading with negative impacts on sexual behavior. In addition, no clear guidance is available on the method or language to use when discussing sexuality issues, leaving messages passed to individual interpretations [4]. Sexually explicit media content with no accompanying pregnancy prevention messages has also been found to foster negative attitudes and beliefs in adolescents [5]. Adolescents also make decisions about sex based on insufficient knowledge [6-9].

This paper uses a case study from Nairobi, Kenya, to discuss adolescents' perceptions towards contraception.
The paper also links information from adolescents with information from parents and schools to establish factors in the socialization environment that influence adolescents' perceptions on contraceptive use.

Although awareness of contraceptive methods in Kenya is above 90 percent, only 5 percent of adolescents aged 15 - 19 years use contraceptives [10]. Low use of contraceptives impacts on fertility and maternal mortality. Several studies estimate that about 15 million babies are born to adolescent mothers each year and that 8 out of 10 of these babies are born in developing countries [11-14]. In Kenya, adolescent fertility is high and child bearing increases from 2 percent at age 15 to 36 percent at age 19 [10]. Pregnancies among adolescents lead to complications of birth due to incomplete physiological body growth, anemia, inadequate knowledge, and low use of reproductive health services. Engaging in unprotected sex increases the risk of contracting sexual transmitted infections (STIs) and to unwanted pregnancies. Unwanted pregnancies lead to girls dropping out of school and to unsafe abortion with the attendant health complications and sometimes death. Furthermore, dropping out of school contributes to negative socio-economic effects for the girl resulting in poor quality of life when she cannot se- 
cure paid employment to enable her adequately cater for her own needs and those of the child.

The social and physical environment affects adolescents' perceptions of reproductive health and contraceptive use. Maternal approval, for example, has been associated with a higher probability of birth control use among adolescents $[15,16]$. However, in many traditional cultures sexual activities are sanctioned only in marriage. With the breakdown of the social structures traditionally used to educate young people on sexuality in Africa, adolescents are becoming sexually active without adequate guidance. For example, in a study conducted in Nigeria only 39 percent of parents surveyed had discussed issues of sexuality with their children [17]. Another study carried out through focus group discussions in Nigeria to find out why adolescents seek abortion rather than contraception found that low levels of contraceptive use among young people arise from their perceived risk of side effects $[7,18]$. For example, other than condoms, the youth understood contraceptives to mean something that interferes with fertility, while abortion had similar but short-lived effects. Although the youths got contraceptive supplies from medicine stores, which were seen to be discrete and confidential, the dealers of the stores provided minimal or no information on the exact nature of known effects or benefits of the available methods [7]. Service providers may also have negative perceptions about providing contraceptives to unmarried adolescents [19]. In a study conducted in Kenya and in Zimbabwe [20], adolescents indicated that staff attributes was one of four main characteristics that they valued in a service facility. However, in Kenya, only 7 percent of health facilities are youth friendly [21] and this limits access to reproductive health services.

According to Gage [22], birth control is influenced by an adolescent's perception of how socially acceptable their knowing about sex is. In Malawi, the culturally formed and deep rooted need for a man to prove his virility often means that having intercourse without protecttion was of symbolic importance [23]. In Bolivia [19] adolescents' perception of contraceptive use by their partners or peers were found to be both positive and negative and therefore, important in influencing contraceptive use. In Pakistan spousal communication about contraception and related issues was associated with contraceptive use [24]. A review of the literature indicates that male partners have potential to influence their sexual partners in reproductive decisions and it is critical to understand male perceptions towards contraceptive use [25]. In South Africa males disapproved of using contraceptives because they were afraid of losing control over their girlfriends [18]. A qualitative study on condom use and risk perception among male and female adolescents in Cameroon showed that despite high levels of awareness on
HIV/AIDS, risk perceptions remained low and 73 percent of males and 68 percent of females believed that they were at no risk or they were at lesser risk of contracting HIV/AIDS than were other adolescents [26].

The family and school are the main socialization institutions in a community. Society expects these institutions to pass information and to guide growing children on values. The institutions are therefore critical in influencing perceptions. However, there is inadequate literature linking information on contraceptive use between adolescents, parents and teachers. There is also inadequate literature on factors that influence perceptions and how these factors are influenced by the environment in which adolescents are socialized. According to perception formation theory, adolescents develop values and knowledge from their immediate physical and social environment which in turn influences perception and the behavior to seek services. This paper therefore seeks to discuss perceptions that influence contraceptive use among adolescents in the Kenyan context. The paper also establishes factors that influence adolescents' perceptions and how those perceptions have an impact on contraceptive use.

\section{Methods}

This paper draws on primary data collected from a crosssectional household survey, using both quantitative and qualitative methods including semi-structured interview, in-depth interview and focus group discussions. An inclusion criterion for the sample was 15 - 19 years old males and females living in Nairobi at the time of the study. A total of 15 in-school, 13 out-of-school and 15 married out-of-school adolescents attended the focus group discussions (FGDs). Another 12 parents also attended FGDs. In addition, 137 parents and 42 teachers from 30 secondary schools attended the in-depth interviews (IDIs). The study interviewed 1159 people out of whom 1119 completed the questionnaires successfully, a 96.5 percent success rate. From the adolescents interviewed, 519 (46.2 percent) were males and 600 (53.8 percent) females.

The sampling frame was the total projected population of adolescent males and females 15 - 19 years in Nairobi based on the 1999 census and the 2009 Kenya Demographic and Health Survey (KDHS) enumeration clusters. Systematic random sampling was used. To determine the number of adolescents to interview, a probability sample using a normal sampling distribution was used. We used a 95 percent confidence level, a confidence interval of 3 and a relative standard error of 10 percent, from a projected population of 280,400 (159,600 females and 120, 600 males). To be able to estimate the number of clusters to use, the projected number of adolescents $(280,400)$ 
was proportionally allocated among the 4476 enumeration clusters of 651,861 total households using the 1999 census. Forty percent of the clusters were randomly selected to fulfill the study sample requirements.

The study used triangulation of information from both quantitative and qualitative methods to enrich the findings. While the qualitative methods were important in gathering information on causal context of contraceptive use among adolescents and some of the challenges and enablers, quantitative methods were used for statistical analysis. To measure perceptions the respondents were asked the following four questions: How would your guardian/parents feel about your using birth control if you were not married? What would you say is your opinion about unmarried youth using a contraceptive method to avoid getting pregnant? If you wanted to, could you yourself get a contraceptive method? Would you say that you know how contraceptives are used? How often have you discussed contraceptives with your partner in the past one year?

Qualitative data were used to establish the nature of discussions on sexuality and contraceptive use held in schools and by family members, and the messages passed during these discussions and how the messages contribute to forming perceptions. Teachers identified for IDIs included those allocated counseling duties and any other person identified by the administration who counseled students. Where the head teacher was also the school counselor, only one teacher was interviewed in that school. Parents were identified from individual adolescent questionnaires. Only willing parents of participating adolescents were interviewed. Out of 137 parents in IDIs, only 29 male parents agreed to be interviewed while the rest were females. Parents were interviewed during the same period individual respondent questionnaires were administered. Parents were interviewed separately where both were available in the household.

Approvals were obtained from the University Board of Post Graduate Studies, the National Council for Science and Technology Ethics and Protocols Board, the Kenya National Bureau of Statistics (to be able to use enumeration areas maps) and the Nairobi Provincial Commissioner's office for data collection in the community. The area administrative chiefs in their locations allocated community leaders to accompany the research team during the household listing exercise. Ethical considerations were adhered to for participants' rights and confidentiality. The team explained the study objectives to participants who gave verbal or written consent. Parents gave permission for their adolescents to participate, but the participating adolescents had to give final consent. A team of research assistants who were conversant with data collection in the same environment were trained to support the study.
The quantitative data were analyzed using the Statistical Package for Social Scientists (SPSS) version 17. Qualitative data analysis involved thematic content examination of the memos, using Atlas Ti coding strategy and the continual investigation of the themes for categories, linkages and properties. Verbatim quotations were used to illustrate responses.

The study had limitations in collecting the information related to sexuality issues. It was a challenge to mobilize adequate numbers of sexually active adolescents by administrative divisions. They could not therefore be grouped according to administrative division based on where they lived. The participants willing to attend FGDs were requested to meet in a common place convenient to them. The information collected was sensitive as it focused on sexuality and therefore, it was not possible to cross-check across causal inferences due to the social desirability bias.

\section{Findings}

\subsection{Results of the Analysis}

Contraceptive use was found to be low: only 8.6 percent of adolescents interviewed used any method. Table 1 gives characteristics of adolescents by background factors in the sample population. Never married adolescents were 98.3 percent compared with 1.7 percent ever married. Most adolescents (75.9 percent) lived with their parents; 86.6 percent were in school. The most important source of sexuality information for most adolescents was the teacher (67.1 percent) followed by other sources (17.6 percent) and then parents (15.3 percent). Majority of adolescents (62.1 percent) lived in medium socioeconomic status households.

Although majority of the respondents lived with their parents, this finding was expected as most of the adolescents at this age are in school and therefore dependent on their parents. Although the finding of this study showed that the main important source of sexuality information was the teacher, narratives indicated that teachers were not prepared to provide accurate information on the risks of unprotected sex. In addition, although majority of the adolescents lived with their parents, they were rated as the least source of sexuality information. Furthermore, narratives from FGDs and IDIs indicated that most of the discussions at home and in school did not focus on preventing unplanned pregnancies.

Majority of the adolescents lived in medium socioeconomic status households. However, the study findings found no significant difference in contraceptive use among adolescents living in different levels of socioeconomic status probably due to family planning programs being implemented in the low resource areas that are likely to reduce costs of contraceptive use by making 
Table 1. Percentage distribution of selected background characteristics according to the sample population: Nairobi, Kenya, 2010 ( $N=1119)$.

\begin{tabular}{|c|c|}
\hline Characteristics & $\%$ \\
\hline \multicolumn{2}{|l|}{ Contraceptive use } \\
\hline Never use & 91.4 \\
\hline Ever use & 8.6 \\
\hline \multicolumn{2}{|l|}{ Age } \\
\hline 15 & 21.7 \\
\hline 16 & 21.8 \\
\hline 17 & 24.0 \\
\hline 18 & 21.0 \\
\hline 19 & 11.4 \\
\hline \multicolumn{2}{|l|}{ Sex } \\
\hline Male & 46.4 \\
\hline Female & 53.6 \\
\hline \multicolumn{2}{|l|}{ Marital status } \\
\hline Never married & 98.3 \\
\hline Ever married & 1.7 \\
\hline \multicolumn{2}{|l|}{ Living arrangement } \\
\hline With parents & 75.9 \\
\hline With spouse & 1.3 \\
\hline With other people/Elsewhere & 22.1 \\
\hline No information & 0.7 \\
\hline \multicolumn{2}{|l|}{ Attending school } \\
\hline In school & 86.6 \\
\hline Out of school & 11.5 \\
\hline Not information & 1.9 \\
\hline \multicolumn{2}{|c|}{ Most important source of sexuality information } \\
\hline Teacher & 67.1 \\
\hline Parent & 15.3 \\
\hline Other sources & 17.6 \\
\hline \multicolumn{2}{|l|}{ Socio-economic status } \\
\hline High & 27.1 \\
\hline Medium & 62.1 \\
\hline Low & 10.8 \\
\hline Source: Primary analys & \\
\hline
\end{tabular}

services more accessible in the community.

Table 2 shows differentials in contraceptive use among adolescents in the study. Compared by sex, more males than females used contraceptives probably because more adolescents preferred condoms to other types of contra-
Table 2. Differentials in contraceptive use by perception variables, Nairobi, Kenya, 2010 ( $\mathrm{N}=1119)$.

\begin{tabular}{|c|c|c|c|}
\hline Factors & $\begin{array}{l}\text { Ever use } \\
\text { (percent) }\end{array}$ & $\begin{array}{l}\text { Never use } \\
\text { (percent) }\end{array}$ & $\begin{array}{l}\text { Total number } \\
\text { of cases }\end{array}$ \\
\hline \multicolumn{4}{|l|}{$\begin{array}{l}\text { Contraceptive } \\
\text { use by sex }\end{array}$} \\
\hline & $* *$ & & \\
\hline Male & 10.6 & 89.4 & 519 \\
\hline Female & 6.8 & 93.2 & 600 \\
\hline \multicolumn{4}{|l|}{ Perceptions } \\
\hline $\begin{array}{l}\text { Parent/guardian would } \\
\text { approve contraceptive use } \\
\text { for unmarried youth }\end{array}$ & $* * *$ & & \\
\hline Would object & 6.2 & 93.8 & 728 \\
\hline Would not object & 17.7 & 82.3 & 237 \\
\hline Other response & 5.8 & 94.2 & 154 \\
\hline $\begin{array}{c}\text { Opinion of } \\
\text { unmarried youth to } \\
\text { use contraceptives }\end{array}$ & $* * *$ & & \\
\hline Approve & 23.3 & 76.7 & 266 \\
\hline Disapprove & 4.2 & 95.8 & 756 \\
\hline Not sure & 2.4 & 97.6 & 82 \\
\hline No information & 0.0 & 100 & 15 \\
\hline $\begin{array}{l}\text { Can get contraceptives } \\
\text { for self if wanted to }\end{array}$ & $* * *$ & & \\
\hline Yes & 23.3 & 76.7 & 266 \\
\hline No & 4.2 & 95.8 & 756 \\
\hline No information & 2.1 & 97.9 & 97 \\
\hline $\begin{array}{l}\text { Knows how } \\
\text { contraceptives are used }\end{array}$ & $* * *$ & & \\
\hline Yes & 19.0 & 81 & 490 \\
\hline No & 0.5 & 99.5 & 604 \\
\hline No information & 0.0 & 100 & 25 \\
\hline $\begin{array}{l}\text { Partner communicates } \\
\text { about contraceptives }\end{array}$ & $* * *$ & & \\
\hline $\begin{array}{l}\text { Communicates } \\
\text { with sexual partner }\end{array}$ & 77.2 & 22.8 & 79 \\
\hline $\begin{array}{l}\text { Never communicates with } \\
\text { sexual partner }\end{array}$ & 47.7 & 52.3 & 65 \\
\hline No information & 0.4 & 99.6 & 975 \\
\hline
\end{tabular}

Notes: ${ }^{* * *} \mathrm{p}<0.01,{ }^{* *} \mathrm{p}<0.05,{ }^{*} \mathrm{p}<0.1$, ns: not significant.

ceptive methods since condom use is promoted in programs for the prevention of HIV/AIDS programs [10]. The main perceptions affecting contraceptive use were: parental approval, adolescents' approval of the use of contraception, knowledge on how to use a contraceptive method, ability to get a contraceptive for self and partner communication. Parents and teachers had negative perceptions on contraceptive use. Although teachers and 
parents were among the main sources of sexuality information, the results from FGDs and IDIs indicated that the messages they gave focused on discouraging adolescents from using contraceptives. Consequently, differentials in contraceptive use showed that adolescents who received sexuality information from teachers and parents used contraceptives less that those who received sexuality information from other sources.

\subsection{Perceptions on Parental Approval and the Influence of Sexuality Messages on Contraception}

Table 2 shows the results of perceptions on contraceptive use. The findings show that parental approval was significantly associated with contraceptive use at $\mathrm{p}<0.01$. Contraceptive use increased from 6.2 percent among adolescents whose parents would object to 17.7 percent among adolescents whose parents would not object. These results imply that parental approval is an important determinant of contraceptive use among adolescents in the study area. Similar findings are found in other studies $[9,16,27]$.

Parents are a product of society and their values are likely to influence adolescents' perceptions on contraceptive use. The findings also show that slightly more females (52.7 percent) than males (47.3 percent) felt their parents would object to contraceptive use (Table 3 ).

The results of the qualitative analysis supported those of the quantitative analysis on the association of parental approval and contraceptive use. During IDIs, few parents indicated they talked about the advantages of contraceptives with their teenage children and cited disadvantages of contraceptives as their main focus of discussion. Most respondents among the parents indicated that if they found their daughters or sons with a contraceptive, they would be annoyed. In the FGD narratives, parents also expressed negative perceptions about contraceptive use among adolescents. These perceptions were contrary to the general consensus about the topics they indicated in IDIs as important to discuss at home which included preventing pregnancy and HIV/AIDS. One parent noted: I cannot allow this (use of contraceptives) to happen in my house. This thing (contraceptives) is a health hazard. That is what I shall tell her (daughter). Family planning destroys one's body. From personal experience, I can appeal to my daughter not to use contraceptives (female parent in FGD session).

Although messages passed during socialization are expected to shape values and therefore behavior, some parents and teachers indicated that they lacked adequate knowledge and skills to communicate sexuality issues with their growing children. This finding shows that parents and teachers do not give adequate information on reproduction and pregnancy prevention to adolescents.
Table 3. Differentials in contraceptive use by perception variables and by sex, Nairobi, Kenya, 2010 ( $N=1119)$.

\begin{tabular}{|c|c|c|c|}
\hline Factors & $\begin{array}{c}\text { Males } \\
\text { (percent) }\end{array}$ & $\begin{array}{l}\text { Females } \\
\text { (percent) }\end{array}$ & $\begin{array}{l}\text { Total number } \\
\text { of cases }\end{array}$ \\
\hline Perceptions & & & \\
\hline $\begin{array}{l}\text { Parent/guardian would approve } \\
\text { contraceptive use for } \\
\text { unmarried youth }\end{array}$ & ** & & \\
\hline Would object & 47.3 & 52.7 & 728 \\
\hline Would not object & 49.4 & 50.6 & 237 \\
\hline Other response & 37.7 & 62.3 & 154 \\
\hline $\begin{array}{l}\text { Opinion of unmarried } \\
\text { youth to use contraceptives }\end{array}$ & ns & & \\
\hline Approve & 52.6 & 47.4 & 266 \\
\hline Disapprove & 44.7 & 55.3 & 756 \\
\hline Not sure & 42.7 & 57.3 & 82 \\
\hline No information & 40.0 & 60.0 & 15 \\
\hline $\begin{array}{l}\text { Can get contraceptives } \\
\text { for self if wanted to }\end{array}$ & ** & & \\
\hline Yes & 52.6 & 47.4 & 266 \\
\hline No & 44.7 & 55.3 & 756 \\
\hline No information & na & na & 97 \\
\hline $\begin{array}{c}\text { Knows how } \\
\text { contraceptives are used }\end{array}$ & $* * *$ & & \\
\hline Yes & 53.3 & 46.7 & 490 \\
\hline No & 41.1 & 58.9 & 604 \\
\hline No information & 40.0 & 60.0 & 25 \\
\hline $\begin{array}{l}\text { Partner communicates } \\
\text { about contraceptives }\end{array}$ & ns & & \\
\hline $\begin{array}{l}\text { Communicates with } \\
\text { sexual partner }\end{array}$ & 46.8 & 53.2 & 79 \\
\hline $\begin{array}{l}\text { Never communicates } \\
\text { with sexual partner }\end{array}$ & 55.4 & 44.6 & 65 \\
\hline No information & na & na & 975 \\
\hline
\end{tabular}

Notes: ${ }^{* * *} \mathrm{p}<0.01,{ }^{* *} \mathrm{p}<0.05,{ }^{*} \mathrm{p}<0.1$, ns: not significant, na: information not available by sex.

These findings are supported by other studies [17-31]. Male parents also indicated that they lacked the time to discuss sexuality issues with their children and religion did not encourage such discussions. The following excerpts illustrate the inadequacies parents face in communicating sexuality issues with their adolescent children:

We are dealing with growing children who are informed they are now young adults and they know about sex and since they are your own children, you find it embarrassing to discuss issues of sexuality and HIV (male parent in FGD session).

But you know the problem here is that most of the par- 
ents do not know about sex education. They do not even know when a child has started her period or menstruation (male parent in IDI).

Narratives in this study indicated that the Ministry of Education in Kenya has introduced life skills curriculum in schools. However, most of the teachers and parents interviewed indicated that sexuality education in school is inadequate and unstructured. In Kenya the school curriculum does not include subjects on sexuality and contraception and, consequently, adolescents are left to rely on their peers and the media for information on sexual health $[28,31]$. In this study, the teachers who were expected to carry out counseling activities lacked the necessary skills, they felt overburdened and lacked supporting teaching materials. They also did not explain to the students the dangers of unprotected sex. This finding is similar to that of studies done elsewhere. For example, a study carried out in Argentina, Peru and the Philippines also reported that teachers focused on discouraging students from sexual activities without explaining the dangers of unprotected sex [30]. The following interview excerpts illustrate the sexuality education environment in schools in Kenya:

Nobody is handling the subject adequately. Schools lack proper curriculum, qualified teachers, and time. They (schools) lack books and facilities (female counseling teacher).

We tend to put what we call don'ts we do not get into details. We just say, do not do this, but nobody sits down with the students to talk to them about their body changes their sexual urges and most of the time we just say $\mathrm{OK}$, this is the human body these are the changes that you go through. If it is religious subject, they (teachers) just say sex is bad the problem we have is that nobody tells them (students) that in marriage sex is not wrong nobody tells them that they are students and they will have those urges (Female counseling teacher).

Another study supports the need to equip teachers with the skills necessary to counsel adolescents: a well prepared teacher was able to comfortably share experiences of sexuality and to make a classroom a safe space for dialogue [29].

\subsection{Adolescents' Opinion on Contraceptive Use by the Youth}

Consistent with other studies [27], the findings showed that perceptions on adolescents' approval to use a contraceptive was associated with increased use. Contraceptive use rose from 4.2 percent among adolescents who disapproved of use by unmarried youth to 23.3 percent among adolescents who approved of use (Table 2). However, when the results were compared by sex neither the opinions of males nor females were statistically significant although more males than females approved of us- ing contraception (Table 3).

Males and females expressed different opinions on contraceptive use. Adolescents in FGDs indicated that using contraceptives was a sign of maturity and of being responsible. However, some adolescents' disapproved because they felt that contraceptive use would make adolescents careless. The following excerpts illustrate different perceptions about contraceptive use by the adolescents:

I would be comfortable if my girl-friend asks me to use condoms because I don't want to spoil both our lives. I will be glad because she will not get pregnant (inschool, 18-year-old male adolescent).

For me, adolescents should not even be given information on contraceptives because this can make them become careless (15-year-old, in-school female adolescent).

\subsection{Ability to Get Contraceptives by the Adolescents}

The association between the ability to get contraceptives for oneself and ever use of contraceptive was statistically significant. In the bivariate analysis (Table 2) ever use of contraceptive increased from a low of 4.2 percent among adolescents who could not get contraceptives for self to a high of 23.3 percent among adolescents who could get contraceptives for themselves. The result implies that ability to get contraceptives for oneself is a significant determinant of contraceptive use among adolescents in the study area. In Kenya parents and religious leaders have for a long time opposed contraceptive use by unmarried youth. Adolescents therefore perceive that the family would disapprove use of contraception and are likely to be afraid of seeking contraceptives for themselves.

Another reason cited for non-use of contraceptives was discrimination against unmarried adolescents by providers. Similar findings have been reported where some health providers in Kenya require a client to be married or have at least one child before giving a contraceptive method [32]. Such misleading information created negative perceptions about contraception among adolescents and discouraged them from seeking services from health facilities. Many adolescents in FGDs reported that service providers both at the health facilities and other outlets had negative perceptions and were reluctant to supply contraceptives to adolescents on account of age. For example, according to in-school adolescents, clinics do not provide contraceptives to clients younger than 18 years old as illustrated in the following narratives.

According to the doctor at the clinic it is not good to use contraceptives before you get two children (in-school, 17-year-old female adolescent).

Some hospitals ask for identification cards before you are attended at my age I do not have a national identifi- 
cation card (in-school, 16-year-old female adolescent).

The findings obtained from IDIs and FGDs illustrate that most adolescents have negative perceptions on contraceptive use out of mistrust, and because they are afraid of the imagined embarrassment should other peers find out about their contraceptive behavior. This finding supports that of other studies which report that adolescents are uneasy about their sexuality and feared humiliation by their peers, exposing them to unprotected sex $[19,33]$. More males than females (Table 3) were able to get contraceptives for themselves showing that males are freer to seek contraceptive services. Female respondents in FGDs expressed their fears that sexual partners would discuss them among their friends and this would be construed to be immoral as illustrated in the following quote:

If he asks me to use pills, I would fear that the boy will tell others and this will cause the girl to be embarrassed. They (boys) will wonder what kind of a girl I am (inschool, 15-year-old female adolescent).

\subsection{Knowledge of How Contraceptives Work}

The results indicated that contraceptive use increased with the level of knowledge of how contraceptives are used from 0.5 percent among adolescents who did not know how contraceptives work to 19.9 percent among adolescents who did. However, compared by sex, more males knew how to use contraceptives than female adolescents. Accurate knowledge reduces misconceptions and is an important determinant of contraceptive use consistent with studies carried out elsewhere [8,9,18,22]. Many adolescents in the FGDs also underscored the importance of knowledge in contraceptive use as illustrated in the following quotes:

For me, I would like to be told how to use contraceptives. I would like to know even their negative side so that I can be aware of the effects and make my own decisions on whether to use or not (out-of school, 16-year-old female adolescent).

Some people will not use contraceptives out of ignorance. There are girls who will not use pills because they think that they will get cancer (17-year-old, married female adolescent).

\subsection{Sexual Partner Communication}

Ever use of contraceptives increased with sexual partner communication. According to the respondents, the results indicated that use of contraceptives varied with whether adolescents discussed the issue with their sexual partners. Contraceptive use increased from 47.7 percent among adolescents who never communicated with their sexual partners about contraceptive use to 77.2 percent among adolescents who did. The results imply that partner communication is a significant determinant of contraceptive use. Similar findings were reported in Pakistan where contraceptive use increased when both sexual partners discussed how to prevent childbearing [34]. Narratives from sexually active adolescents in FGDs indicated inconsistencies in their perceptions on contraceptive use. Some of the adolescents were afraid to suggest the use of contraceptives especially condoms as this was viewed as an admission of infidelity. Most adolescents who discussed contraceptives with their sexual partners indicated that this shows a sense of caring as illustrated in the following quotes:

I don't think contraceptive is a subject to discuss with your boyfriend. I think if I discuss with a man, he can go and tell his friends and they will wonder what kind of a girl I am (out-of-school, 17-year-old female adolescent).

If my boy-friend suggests that we should use a contraceptive, this will be ok. It means that he does not want to ruin my life. It means that he cares for me (in-school, 15year-female adolescent).

Although some adolescents will not use contraceptives in marriage, others welcomed the idea. Husbands looked for opportunities to discuss the need for contraceptive use while wives indicated they used indirect communication to show support for contraceptive use as illustrated in the following:

If he (husband) does not quarrel when he finds that I am using a contraceptive, I will know he is OK with them (contraceptives) and he supports (18-year-old female married adolescent).

When you see a neighbor get a child too soon that is when you say it is better to start using them (contraceptives) because next it will be happening (pregnancy) in your own house that is when I will tell her (wife) to look at what happened to the neighbor (19-year-old married male adolescent).

\section{Discussion}

Although the study was carried out in one of the provinces (counties) in Kenya, the results provide some insight about the common perceptions adolescents have, some of the contributing factors towards forming those perceptions and the impact of the perceptions on contraceptive use among adolescents. Our findings show that perceptions influence contraceptive use outcomes and that messages passed by peers, parents and teachers are factors that affected contraception behavior among adolescents. This finding supports the perception formation theory [1-3] which explains that behavior is influenced by information from the immediate physical and social environment. This theory also conforms with the theory of reasoned action proposed by Fishbein and Ajzen [35] which postulates that behavior is influenced by several factors among them, one's assessment that a particular 
behavior is desired by significant others and a motivation to comply with views of significant other people in their life environment who in this case would be the family, teachers and peers [3]. Complying with the wishes of significant others would mean that adolescents would take action or not to prevent an unwanted pregnancy by using contraception.

Approval by significant others in society affect decisions made by adolescents on contraceptive use. For example, a higher number of adolescents using contraceptives had parental approval, approved use of contraceptives by the youth, knew how to use contraceptives, communicated with sexual partners and, could get contraceptives for themselves. The study found more males than females used contraceptives probably because parents are likely to monitor their sons less on sexuality issues than they would their daughters. This could reinforce male control on sexual and reproduction decision making and also influence a girls' ability to make decisions on contraceptive use as reported by Gage [22] in her study on sexual activities and contraceptive use in the decision-making process.

With the breakdown of family units especially in the urban areas, sexuality education remains a big challenge for parents. Narratives indicated that parents and teachers had negative perceptions and they focused their messages on the negative effects of contraceptives because they lacked the knowledge and skills to pass information on sexuality and reproductive health to adolescents. This has a negative influence on adolescents' use of contraception. Parents also reported that it was a challenge for them to identify the correct words to use when discussing sexuality issues with their children. To influence positive perceptions, strategies must be developed to educate parents on adolescents' sexual and reproductive health issues with age specific messages that can influence adolescents' positive perception on contraceptive use. In addition, programs should focus on messages that show how contraceptives work, where to get contraceptives and on making contraceptives and information more accessible. Accurate information on sexuality would enhance positive perceptions and informed decision making on contraception by adolescents.

When school curriculums do not include subjects on sexuality and contraception, adolescents have to rely on their peers and the media for information on sexual health as indicated in the national information, education and communication situation survey [28,31]. Information from peers may not always be accurate as illustrated by this quote made by a male adolescent in a study carried out in South Africa "guys pretend to be knowing how to use condoms even when they don't" [36]. Education policies should therefore be reviewed to integrate more comprehensive and age specific messages on sexuality and reproductive health. It is also important to build capacity of teachers with necessary knowledge and skills and other appropriate materials to support sexuality education. Sexuality education should also be examined in schools to ensure access to more comprehensive sexuality and reproductive health information including pregnancy prevention.

The narratives from this study showed that service providers had negative perceptions and they discouraged contraceptive use through misinformation on the effects of contraceptives on adolescents' health. This contributed to negative perceptions by adolescents. There is need therefore to improve service provider skills on quality adolescent sexual and reproductive health services that are youth-friendly.

The results of the multivariate regression analysis (results not shown here) also showed that knowing how to use contraceptive methods and partner communication were positive perception attributes with the most statistically significant effect. These attributes were therefore, major determinants of contraceptive use among all perception factors. Consistent with other studies [34], this study demonstrated the importance of sexual partner communication in contraception outcome. Programs should therefore focus on strategies that encourage sexual partner communication on sexuality issues and increased knowledge on how to use contraceptives among both female and male adolescents.

\section{Conclusions}

To enhance positive perceptions by adolescents, strategies must be developed to educate parents on adolescents' sexual and reproductive health issues with age specific messages that would enhance positive attitudes so that the family can support contraceptive use by adolescents. To enhance adolescents' positive perception on contraception, it is important to educate them and build their confidence in the decision-making process through focusing on messages that show how contraceptives are used and where to get contraceptive services. In addition, it is important to build capacity of schools to educate their students on sexuality and reproductive health issues including contraception to positively change adolescents' perceptions on contraceptive use. Adolescents should also be encouraged to discuss use of contraception with their sexual partners. To reduce misconceptions passed to adolescents by providers, service provider skills must be improved so they can give quality adolescent sexual and reproductive health services that are youth-friendly. Further research is also important to identify and develop age specific messages to guide school education curriculums and equip parents with the messages necessary to enhance a parent-child communication program.

The study showed that teachers were the main source 
of sexuality information among adolescents. However, teachers were found to have negative perceptions on contraceptive use by adolescents. These findings have implications on the role of the teacher in the influence of population policy through providing comprehensive sexuality information in school. Integrating comprehensive information on sexuality with reproductive health information would enhance informed decision making on preventing unwanted pregnancy and on promoting healthy sexuality behavior among adolescents. The sexuality education curriculum must therefore be reviewed or developed and supported with teaching materials

\section{Acknowledgements}

This article was developed from a Ph.D. thesis on "Perceptions and Barriers to Contraceptive Use Among Adolescents: A Case Study of Nairobi” conducted through the Population Studies and Research Institute, University of Nairobi. The work was supported by the African Doctoral Dissertation Research Fellowship offered by the African Population and Health Research Centre (APHRC) in partnership with the International Development Research Centre (IDRC) and Ford Foundation.

\section{REFERENCES}

[1] K. Glanz, Emory University and M. C. Kegler, “Concepts of the Social Cognitive Theory Health Behavior and Health Education: Theory, Research and Practice,” Wiley and Sons, San Francisco, 2002.

[2] W. Derrel, “Selective Perception,” 2000. http://www.ciadvertizing.org

[3] A. Bandura, "Social Foundations of Thought and Action,” Prentice-Hall, Inc., Englewood Cliff, 1986.

[4] C. Undie, J. Crichton and E. Zulu, "Metaphors We Love By: Conceptualizations of Sex among Young People in Malawi,” Africa Journal of Reproductive Health, Vol. 11, No. 3, 2007, pp. 221-235. doi:10.2307/25549741

[5] G. Wingood, J. Ralph, K. Harrington, W. Edward and M. Kim, "Exposure to X-Rated Movies and Adolescents' Sexual and Contraceptive-Related Attitudes and Behaviors,” Pediatrics, Vol. 107, No. 5, 2001, pp. 1116-1119. doi:10.1542/peds.107.5.1116

[6] Q. Nahar, C. Tuñón, I. Houvras, R. Gazi, M. Reza, N. Huq and B. Khuda, "Knowledge Attitudes and Practice of Adolescents Relating to Contraceptive Use,” 12th Annual Scientific Conference in Bangladesh, Dhaka, 2000.

[7] V. O. Otoide, F. Oronsaye and F. E. Okonofua, "Why Nigerian Adolescents Seek Abortion Rather than Contraception: Evidence from Focus Group Discussions,” International Family Planning Perspectives, Vol. 27, No. 2, 2001, pp. 77-81. doi:10.2307/2673818

[8] K. Kiragu and L. S. Zabin, "Contraceptive Use among High School Students in Kenya,” International Family Planning Perspectives, Vol. 21, No. 3, 1995, pp. 108-113. doi:10.2307/2133184
[9] S. Ryan, K. Franzett, J. Manlove and E. Hokombe, "Knowledge, Perceptions and Motivation for Contraception: Influence on Teens' Contraceptive Consistency," Youth and Society, Vol. 39, No. 2, 2007, pp. 182-208. doi:10.1177/0044118X06296907

[10] Kenya National Bureau of Statistics (KNBS) and ICF Macro, "Kenya Demographic and Health Survey 20082009,” KNBS and ICF Macro, Calverton, 2010.

[11] Advocates for Youth Organization, "The Facts: Adolescent Protective Behaviors: Abstinence and Contraceptive Use,” 2007. www.advocatesforyouth.or/publications/factsheet

[12] K. A. Moore and B. W. Sugland, "Using Behavioral Theories to Design Abstinence Programs," Children and Youth Services Review, Vol. 19, No. 5-6, 1997, pp. 485500. doi:10.1016/S0190-7409(97)00029-7

[13] United Nations Population Fund, "Population Issues: Briefing Kit,” 2001, pp. 9-17.

[14] S. Alford, N. Cheetham and D. Hauser, "Science and Success in Developing Countries: Holistic Programs that Work to Prevent Teen Pregnancy, HIV and Sexually Transmitted Infections,” Advocates for Youth, Washington DC, 2005.

[15] L. A. Hulton, R. Cullen and S. W. Khalokho, "Perceptions of the Risk of Sexual Activity and Their Consequences among Ugandan Adolescents," Studies in Family Planning, Vol. 31, No. 1, 2000, pp. 35-46 doi:10.1111/j.1728-4465.2000.00035.x

[16] J. Jaccord and J. D. Patricia, “Adolescent Perceptions of Maternal Approval of Birth Control and Sexual Risk Behavior," America Journal of Public Health, Vol. 90, No. 9, 2000, pp. 1426-1430. doi:10.2105/AJPH.90.9.1426

[17] C. O. Izugbara, "Home-Based Sexuality Education: Nigeria Parents Discussing Sex with Their Children," Sex Education, Vol. 39, No. 4, 2007, pp. 575-600.

[18] T. E. Oni, E. A. M. Prinsloo, J. D. Nortje and G. Joubert, "High School Students, Practices and Knowledge of Contraception in Jozini, KwaZulu-Natal," South Africa Family Planning Practice, Vol. 47, No. 6, 2005, pp. 54-57.

[19] L. R. de Belmonte, E. Z. Gutierrez, R. Magnani and V. Lipovsek, "Barriers to Adolescents' Use of Reproductive Health Services in Three Bolivian Cities," Focus on Young Adults/Pathfinder International, Washington DC, 2000.

[20] A. S. Erulkar, C. J. Onoka and A. Phiri, "What Is Youth Friendly Adolescent's Preferences for RH services in Kenya and Zimbabwe,” Africa Journal of Reproductive Health, Vol. 9, No. 3, 2005, pp. 51-58. doi:10.2307/3583411

[21] National Coordinating Agency and Population Development (NCAPD), Ministry of Medical Services (MOMS), Ministry of Public Health and Sanitation (MOPHS), Kenya National Bureau of Statistics (KNBS), "ICF Macro 2011. Kenya Service Provision Assessment Survey 2010,” Nairobi, Kenya: National Coordinating Agency and Population Development, Ministry of Medical services, Ministry of Public Health and Sanitation, Kenya National Bureau of Statistics, and ICF Macro.

[22] A. J. Gage, "Sexual Activity and Contraceptive Use: The 
Components of the Decision Making Process," Studies in Family Planning, Vol. 29, No. 2, 1998, pp. 154-166. doi:10.2307/172156

[23] C. O. Izugbara, "Home-Based Sexuality Education: Nigeria Parents Discussing Sex with Their Children," Youth and Society, Vol. 4, No. 1, 2008, pp. 63-79.

[24] J. B. Casterline, Sathar, A. Zeba A, U.L.Haque, Minhaj , "Obstacles to Contraceptive Use in Pakistan: A Study in Punjab,” Studies in Family Planning, Vol. 32, No. 2, 2001, pp. 95-110. doi:10.1111/j.1728-4465.2001.00095.X

[25] B. E. Whitley and J. W. Schofield, "A Meta Analysis of Research on Adolescent Contraceptive Use,” Population and Environment, Vol. 8, No. 3-4, 1986.

[26] A. E. Calves and A. W. Mellon, "Condom Use and Risk Perception among Male and Female Adolescents in Cameroon: Qualitative Evidence from Edea,” Working Paper No. 22, PSI Research Division, 1999.

[27] D. Meekers and M. Klein, "Determinants of Condom Use among Young People in Urban Cameroon," Studies in Family Planning, Vol. 33, No. 4, 2002, pp. 335-346. doi:10.1111/j.1728-4465.2002.00335.x

[28] E. H. O. Ayiemba, "The Effect of Health Education Programs on Adolescents Sexual Behavior: A case Study on Nairobi City Adolescents," African Population Studies, Vol. 16, No. 1, 2001, pp. 87-103.

[29] J. W. Khamasi and C. Undie, "Teaching Human Sexuality in Higher Education: A Case from Western Kenya,” In: M. Dunne, Ed., Gender, Sexuality and Development: Education and Society in Sub-Saharan Africa, Sense Publishers, Rotterdam, 2008, pp. 189-196.
[30] A. D. Brown and J. Shireen, "Sexual Relations among Young People in Developing Countries: Evidence from World Health organization Case Studies,” Occasional Paper, Department of Reproductive Health and Research, World Health Organization, Geneva, 2001.

[31] National Council for Population and Development (NCPD), "Reproductive Health Communication in Kenya: Results of a National Information, Education and Communication Situation Survey,” Republic of Kenya, Nairobi, 1977.

[32] L. Ndhlovu, R. M. Solo and K. Miller, “An Assessment of Clinic Based Family Planning Services in Kenya: Results from the 1995 Situation Analysis Study,” Population Council's Africa Operations Research and Technical Assistance, Nairobi, 1997, pp. 19-28.

[33] C. O. Izugbara and C. Undie, "Masculinity Scripts and the Sexual Vulnerability of Male Youth in Malawi," International Journal of Sexual Health, Vol. 20, No. 4, 2008, pp. 2-12.

[34] M. Alauddin, "Reaching Newlywed and Married Adolescents," Family Health International, 1999. http://www.fhi.org/en/youth/youthnet/publications/focus/ newlywedandmarried.htm

[35] M. Fishbein and I. Ajzen, "Understanding Attitudes and Predicting Social Behavior,” Preventive-Hall, Inc., Englewood Cliffs, 1980.

[36] T. M. M. Maja, "Factors Impacting on Contraceptive Use among Youth,” University of Johannesburg, Johannesburg, 2007. 